\title{
Self-sacrificing mothers as revered deities of social policy initiatives: reflections on the Huastec mother goddess and conditional cash transfer programmes
}

MELISA HANDL*

Faculty of Law, University of Ottawa

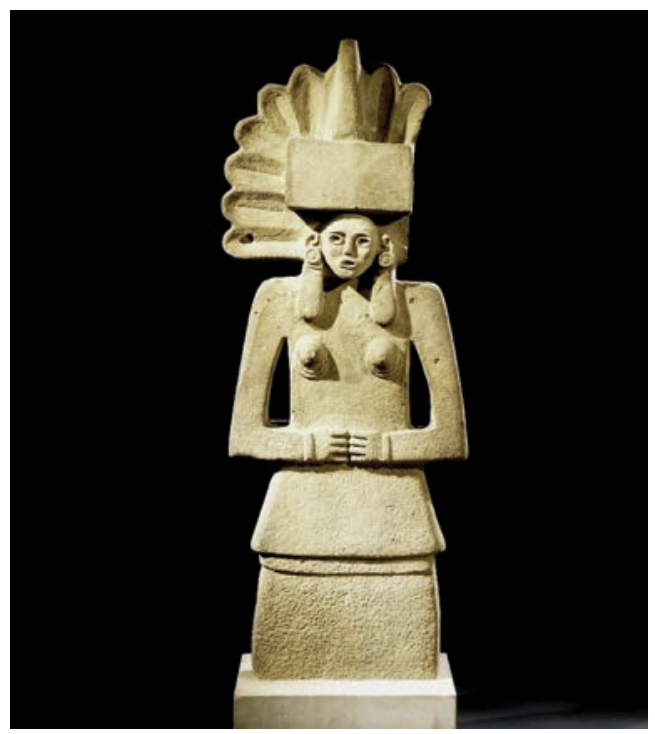

Tlazolteotl

(C) Trustees of the British Museum $\dagger$

\section{Abstract}

This paper explains how an object - a sculpture of a Huastec goddess - has caused me to reflect differently on my doctoral dissertation work and how it has contributed to my research by helping to challenge and develop existing qualitative research methods used in my project. My research project investigates gender equality in the context of conditional cash transfers in Argentina in order to investigate whether they are empowering women. The sculpture of the Huastec Goddess has impacted on my research methods in different ways. Firstly, it has allowed me to emphasise the instrumentalisation of beneficiary women. Secondly, the Huastec sculpture has challenged my epistemological assumptions. Finally, the Huastec sculpture as an object moving from culture to culture and ending up in a museum as a collected artifact has encouraged me to think. more carefully about the ethical implications of qualitative research.

Keywords: legal object; qualitative research methods; conditional cash transfers; reflexivity; ethics in research.

Doctoral candidate mhand050@uottawa.ca.

$\dagger \quad<$ www.britishmuseum.org/research/collection_online/collection_object_details.aspx?objectId=476726\& partId $=1>$ 


\section{Introduction}

This paper explains how an object - a sculpture of a Huastec goddess - has caused me to reflect differently on my doctoral dissertation work and how it has contributed to my research by helping to challenge and develop existing qualitative research methods used in my project.

The sculpture of the Huastec goddess has impacted on my research methods in different ways. Firstly, it has allowed me to emphasise the instrumentalisation of beneficiary women and to explain how these women are actually vessels through which resources from the state are delivered to children. Subsequently, these social policy initiatives contribute to promoting and sustaining stereotypes of 'ideal' mothers, 'setting in stone' and entrenching pervasive and oppressive cultural understandings of what womanhood should look like in the context of Argentina. Secondly, the Huastec sculpture has challenged my epistemological assumptions by allowing me to think more carefully about the dynamics between structure and agency, the synergies between nature and nurture, and the possibilities and constraints to individuality versus more communitarian approaches to combating poverty. Finally, the Huastec sculpture, as an object moving from culture to culture and ending up in a museum as a collected artefact, has encouraged me to think more carefully about the ethical implications of qualitative research, about my role as a researcher, and about reflexivity and its limitations - control and dominance.

The paper is organised in three sections. Firstly, I introduce the object in question the sculpture of the Huastec goddess - and I describe its material properties. Secondly, I provide a general outline of the substantive topic that I research - the practice of conditional cash transfer (CCT) programmes in the context of gender equality in Argentina. Thirdly, I explain the methodologies and qualitative research methods which have informed my work to date - institutional ethnography. Finally, I explain how the object in question - the sculpture of the Huastec- has helped me to reflect on the existing methods used in the project.

This paper builds from the notion of 'object' based on Prown's understanding that 'artefacts are primary data for the study of material culture, and, therefore, they can be used actively as evidence rather than passively as illustrations'. ${ }^{1}$ For Prown, the basic assumption of material culture is that 'objects made or modified by man reflect, consciously or unconsciously, directly or indirectly, the beliefs of individuals who made, commissioned, purchased, or used them, and by extension the beliefs of the larger society to which they belonged'. ${ }^{2}$ For the purposes of this paper, 'trace' will be understood in a very broad sense as an object I have created which evidences something I have been trying to convey in the investigation of my object.

\section{The practice of the Asignación Universal por Hijo programme: CCTs and gender equality in the context of Argentina}

My research project investigates gender equality in the context of CCTs in Argentina in order to answer the following question: is the programme Asignacion Universal por Hijo $(\mathrm{AUH})$ empowering or entrapping poor Argentine women? The objective of my research project is to investigate whether CCTs are empowering women, beyond traditional

1 Jules David Prown, 'Mind in Matter: An Introduction to Material Culture Theory and Method' (1982) 17(1) Winterthur Portfolio 1-19, 1.

2 Ibid. 
assessments of the impact of these social programmes on human capital development among poor Argentine households.

The AUH is basically a social programme that involves a governmental transfer of cash to poor households - transferring the money to the mother of the household - on the condition that they make specific investments in the human capital of their children, such as periodic health check-ups, anthropometric monitoring, prenatal and postpartum care for mothers, and children's school enrolment. ${ }^{3}$

In the short run, CCTs are intended to alleviate poverty and boost consumption; in the long-term, they are meant to allow poor families to overcome the trap of intergenerational poverty. Payments are made by means of a debit card, which can be used to either withdraw cash or to pay for purchases. However, the money will only be deposited after all the conditions required by the programme have been met. The conditionalities are twofold. First, children over the age of five must attend school regularly. Second, mothers must comply with the compulsory national vaccination plan and health checks for all children. All children under six must be registered with Plan Nacer, a federal programme that focuses on health coverage for pregnant women and children. ${ }^{4}$

With regard to my preliminary findings, I will shortly anticipate that my research project has led me to answer my research question by stating that the programme AUH is not empowering poor Argentine women. Instead, women are being entrapped in the sphere of domestic responsibilities and stereotyped as inherently 'motherly'. Indeed, the institutionalisation and implementation of the AUH programme has promoted a complex shift in the way we think about poor women within the household. Women are now seen as the 'decision-makers' within the household, but they cannot be said to be 'empowered' to the extent that they have been heavily burdened and trapped into the sphere of domesticity.

As I will develop in more detail below, the sculpture of the mother goddess has impacted on my research agenda because it allows me to emphasise the instrumentalisation of poor women as conduits rather than as beneficiaries of social policy. It lets me demonstrate how these social programmes encourage conservative ideas of womanhood by building on the maternalisation of social policy. The object of the Huastec goddess allows me to visually convey how traditional ideas of women as mothers - specifically, as 'good', self-sacrificing mothers who are solely responsible for the wellbeing of their offspring - have been 'set in stone' by means of a social policy system through which women's subordination is created and perpetuated through sexuality, time poverty and stereotypes of women as primary caretakers.

\section{The sculpture of the Huastec goddess: womanhood as 'set in stone'}

The object that I have chosen is the sculpture of the Huastec goddess displayed in the Mexico Room at the British Museum. This statue was made by the Huastecs, a people conquered by the Aztecs. The Huasteca territory is now northern Mexico. It is believed that this slab-like sculpture of a woman was made between the tenth and the fifteenth centuries. ${ }^{5}$ The statue is about a metre and a half high. The contours of its body are straight lines and hard edges, composed of overlapping geometric shapes. We can see that this woman has been carved out of a very thin piece of sandstone and that this sculpture

3 Decreto 1602/09 [Decree], 'Asignación Universal por Hijo para Protección Social' (2009) El Poder Ejecutivo Nacional Argentino.

4 Ibid.

5 British Museum, 'A History of the World in a 100 Objects' (BBC/British Museum Partnership 2012) <www.britishmuseum.org/explore/a_history_of_the_world/objects.aspx\#69>. 
is less than 15 centimetres thick. The use of sandstone also explains the lack of detail in the sculpture. Sandstone is a volcanic sedimentary rock that is very porous, not being ideal for carvings. ${ }^{6}$

She has her hands folded over her stomach, forming two triangular spaces. Her breasts are symmetrical hemispheres and below the waist she is wearing a rectangular undecorated flat skirt. However, besides her straight and harsh lines, she does have two softening aspects that make her feel more human. We can, indeed, notice lively details in her small head. Her eyes appear to be looking up and to the side towards something and her mouth is open and she seems to be speaking. Her headdress is approximately 10 times bigger in size than her head and it is remarkable to the extent that it must have been an unambiguous statement of who she was at the time the sculpture was carved. Her prominent breasts convey the message that we are talking about an artistic representation of a female. Below her breasts creases of flaccid flesh are noticeable, possibly evidence of maternity, which suggests she is a mother goddess.

\section{Qualitative research methods and methodology: an institutional ethnography of CCTs}

Qualitative research has taken me as a researcher from 'merely dozing' to feeling very passionate about the methodology I have chosen for my project, for it is qualitative research that allows us legal researchers - and researchers in general - to get a glimpse of people's lives and to connect abstract legal ideas and top-down technocratic approaches to the law with the experiences and aspirations of actual groups of people on the ground. With this marvellous opportunity also comes great responsibility, and I am now aware of the ethical challenges, labour-intensive tasks involved, and the obligation we have as qualitative researchers to produce something interesting and accessible, something that we have an obligation to return to the people who allowed us to glimpse into their lives and share their valuable insights and time with us.

In my doctoral dissertation project, I use a feminist socio-legal methodology drawn from Canadian sociologist Dorothy Smith. ${ }^{7}$ The individual experience is the entry point that allows us to see how these practices are being disciplined by, and simultaneously mould, institutional priorities, which Smith calls 'relations of ruling. 8 Institutional ethnography requires me to knit together the knowledge of a diversity of AUH programme actors. Dorothy Smith most recently described institutional ethnography as 'working from people's experience of their own doings, knitting different perspectives and positions together, and exploring the text-based forms of organization [that] provides means of constructing representation of how things work'?

An important contribution by Smith for the purposes of this piece is the notion that texts are the technology by which an individual practice is related to, and helps in moulding, broader institutional practices. To think in these terms allows us to consider the dynamic interrelationship between subjects, objects and the space they inhabit and the transformational consequences of those relationships upon subjects, objects and the larger locales within which they exist and interact.

6 Ibid.

7 Marjorie L DeVault and Liza McCoy, 'Institutional Ethnography: Using Interviews to Investigate Ruling Relations' in Jaber Gubrium and James Holstein (eds), Handbook of Interview Research (Sage 2002) 751, 753.

8 Dorothy Smith, Texts, Facts and Femininity: Exploring the Relations of Ruling (Routledge 1990).

9 Dorothy E Smith, Institutional Ethnography: A Sociology for People (AltaMira Press 2005) ch 8. 
It is crucial to point out that texts are essential for institutional ethnographers; because of their material properties texts help us to understand institutional priorities. Firstly, as Smith argues, 'texts are key to regulating the concerting of people's work in institutional settings in the ways that they impose accountability to the terms they establish' ${ }^{10}$ Secondly, texts are significant because of their reproducibility. Thirdly, texts also offer stability, as they serve as a record of practices. ${ }^{11}$ As they are distributed widely across Argentina, the texts of the AUH will be activated ${ }^{12}$ over and over again across time and space, enabling governance to happen with the magnitude and in the form that we observe today and allowing institutional processes of social policy to occur in a coordinated manner by reaching more than 2 million households in Argentina. ${ }^{13}$ Texts are thus very important in my research project and, as I will explain in the following section, I have used a physical copy of the main text of the AUH Programme - a copy of the decree that institutionalises the programme in Argentina - to cover the traces I have created for this project and to create a visual metaphor - inspired by the idea of ideal womanhood carved and preserved in stone - of beneficiary women as subjects who are created and shaped by social policy.

\section{How has the sculpture of the Huastec goddess enlightened my research project?}

As I previously mentioned, my research project analyses CCT policies in Argentina from a gender perspective. Policy supporters of CCTs explain that, through the income provided by CCTs, poor women are empowered. ${ }^{14}$ Feminist researchers, however, point out that these policies instrumentalise women, as the intended beneficiaries of the programmes are actually women's children. ${ }^{15}$ Women play a crucial role in the institutionalisation of CCTs in Latin America because payments are made to them as the legally responsible beneficiaries on the understanding that this mechanism will yield better outcomes in the quality of life of children.

The sculpture of the Huastec goddess has impacted on my research methods in different ways. Firstly, it has allowed me to emphasise the instrumentalisation of beneficiary women and to explain how women are not beneficiaries of these programmes, but are actually vessels or channels through which resources from the state are delivered to children. Subsequently, these social policy initiatives contribute to promoting and sustaining stereotypes of the beneficiaries of these programmes and, specifically, stereotypes of 'ideal' mothers by 'setting in stone' and entrenching cultural understandings of what womanhood and motherhood should look like in the context of Argentina. Secondly, the Huastec sculpture has challenged my epistemological assumptions by allowing me to think more carefully about the dynamics between structure and agency, the synergies between nature and nurture, and the possibilities and constraints to individuality versus more communitarian approaches to understanding poverty. Finally, the Huastec sculpture, as an object moving from culture to culture and ending up in a museum as a collected artefact, has allowed me to think more carefully

10 Ibid.

11 Marie Campbell and Frances Gregor, Mapping Social Relations: A Primer in Doing Institutional Ethnography (Garamond Press 2002) 31-44.

12 Smith (n 9) ch 8.

13 Currently 3.6 million children and adolescents are beneficiaries of the AUH. ANSES, $<$ www.anses.gob.ar/autopista/asignacion-universalhijo/>.

14 Maxime Molyneux, 'Mothers at the Service of the New Poverty Agenda: Progresa/Oportunidades, Mexico's Conditional Transfer Programme’ (2006) 4 Social Policy and Administration 4.

15 Ibid. 

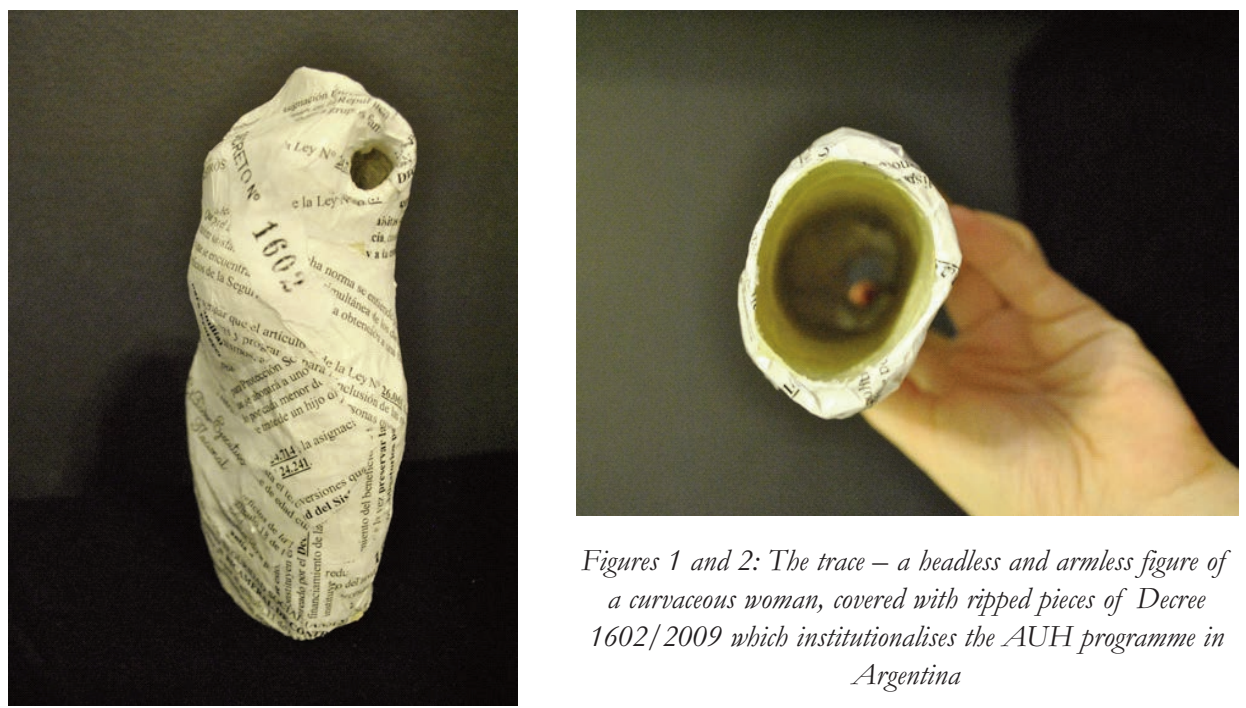

Figures 1 and 2: The trace - $a$ beadless and armless figure of a curvaceous woman, covered with ripped pieces of Decree 1602/2009 which institutionalises the AUH programme in Argentina

about the ethical implications of qualitative research, about my role as a researcher and the dangers of become a 'coloniser', about reflexivity and its limitations - control and dominance - and about the limits and possibilities of language. In the following sections, I will develop in detail each of the three aforementioned reflections.

\section{Set in Stone? Problematising the instrumentalisation of Beneficiary WOMEN AND CONSERVATIVE IDEAS OF 'WOMANHOOD'}

The sculpture of the Huastec goddess displayed at the British Museum allowed me to highlight the instrumentalisation of women beneficiaries of CCTs. Women who are legally entitled to receive the monthly stipend are framed as conduits of social policy through which the state can transfer resources to the poorest sectors of its population. These women are not the real and actual beneficiaries of these social policy initiatives; instead, they are required to ensure the wellbeing of their children and to help train future generations by performing as 'good' mothers.

The Aztecs named the Huastec goddess 'Tlazolteotl' or the 'eater of filth' goddess. Tlazolteotl eats organic waste and excrement and transforms it into healthy new life, safeguarding the cycle of natural regeneration. ${ }^{16}$ In terms of maternity, we enter an area of contradictions and complexities that challenge our traditional dichotomous understandings of the world because an important threat to humankind is the death of mothers and children during childbirth. Therefore, there is an inherent human anxiety linked to giving birth: danger of pollution and subsequent death. Mother goddesses thus originate as a way of relieving this anxiety by helping us understand that life and death can be intimately interlinked and that such false dichotomy is actually no more than a social construct.

In a similarly paradoxical way, women are framed as beneficiaries of CCTs under the rationale that handing the stipend to women is better for the food security of children. Women are therefore framed as responsible for recruiting and training the next generation of poor workers. Beneficiary women are expected to contribute to forming 
their children into self-sufficient, market-oriented, rational, self-actualising individuals. Simultaneously, poor mothers ensure the cycle of social reproduction and help their families escape the trap of the intergenerational transmission of poverty.

The idea of instrumentalisation is a notion I wanted to visually convey and capture in the traces I created. Therefore, I crafted my traces as a hollow object in order to accentuate how women recipients of CCTs are framed as a conduit of policy to deliver a paradigm of human capital development. CCTs' requirements add to women's time burdens and symbolically re-traditionalise them as mothers by using their labour to improve the quantity and quality of future human capital. Using women's unpaid labour and overburdening them is a perverse mechanism that invisibilises poor women's individual needs and erodes their capacities.

As shown in the photographs, my trace is a headless and armless figure of a curvaceous and undoubtedly pregnant woman. I covered my traces with a very particular kind of paper: ripped pieces of a hard copy of Decree 1602/2009 which institutionalises the AUH programme in Argentina. The text of the AUH decree is crucial to my project because it was set up as an ideological pillar in how people in Argentina think about social welfare. Through a disciplinary ideology, it outlines what mothers need to do in order to lift their families out of poverty, namely: travelling and queuing to collect the stipend and to obtain stamps from schoolteachers; regularly attending health-care centres with their children; ensuring children get all appropriate vaccinations; attending workshops on healthcare; preparing household meals and caring for the wellbeing of family members; complying with volunteering activities related to the programmes; transporting their children to school; and ensuring children get appropriate vaccinations. ${ }^{17}$

I wanted the ultra-feminine, curvaceous, pregnant-looking sculpture I created as a trace to capture a hyper-visual representation of the notion of maternalisation of social policy. These social policy initiatives build on the idea of 'pregnant embodiment', that is, on women's more uninterrupted physical experience in relation to children as a result of pregnancy, breastfeeding and caregiving responsibilities. ${ }^{18}$ Motherhood is thus closely seen as a 'natural' result of women's capacity to get pregnant and it is constructed and reproduced by the AUH programme. Thus, the conditionalities imposed upon female beneficiaries also involve pre-natal and postpartum care and checks-up for mothers. The text of the AUH programme, therefore, takes a mother's biological connection with a child and imposes it as an automatic social relationship, naturalising the concept of maternity by amalgamating genetic, gestational and caregiving roles.

I also wanted to suggest that poverty is seen as embodied and hereditary, like a defective gene passed from generation to generation. ${ }^{19}$ Since child poverty is conceived as passed through the female body, the current development discourse highlights women's responsibility. The 'feminisation of responsibility' has resulted in a translation into interventions which have little power to change deeply embedded structures of gender inequality in the home, the labour market and other entities. ${ }^{20}$

17 Decree (n 3).

18 Richard Collier and Sally Sheldon, Fragmenting Fatherhood: A Socio-Legal Study (Hart 2008) 60.

19 Cristina Rojas, 'Governing through the Social: Representation of Poverty and Global Governmentality' in Wendy Larner and William Walters (eds), Global Governmentality (Routledge/Oxford University Press 2004) 97.

20 Sylvia Chant, "The "Feminisation of Poverty" and the "Feminisation" of Anti-Poverty Programmes: Room for Revision?’ (2008) 44(2) Journal of Development Studies 165, 185. 


\section{THE HUASTEC GODDESS SCULPTURE CHALlENGING AND NOURISHING MY EPISTEMOLOGICAL AND ONTOLOGICAL ASSUMPTIONS}

The sculpture has challenged my epistemological assumptions encouraging me to think more carefully about the dynamics between structure and agency, the synergies between nature and nurture, and the possibilities and constraints to individuality versus more communitarian approaches to understanding poverty.

Following the criticalist paradigm, and as my main ontological assumption, I tend to see reality as shaped by political, cultural, economic, racial and gender values, which have formed through history. ${ }^{21}$ I understand that values are formative of my knowledge in a world that is marked by struggles for power. The quality criteria for evaluating my own results is contextualisation. In regards to my posture as an inquirer, I see myself as an intellectual advocate. As a critical researcher, I understand the reasons why my inquiry is constructed as to produce knowledge that can be emancipatory and ignite social change, 'stimulat[ing] oppressed people to rationally scrutinise all aspects of their lives to reorder their collective existence on the basis of the understanding it provides, which will ultimately change social policy and practice'. ${ }^{22}$ Epistemologically - the truth I seek to believe as a researcher - is that while research is driven by power struggles, I truly believe that the knowledge we produce is vitally paramount and capable of modifying current structures of oppression by means of empowerment and social change. ${ }^{23}$

Mauthner and Doucet encourage us researchers 'to be more explicit about the particular epistemological and ontological concepts of subjects that are informing their research practices', ${ }^{24}$ including issues such as whether our subject is relational or individuated, if her/his voice is regarded as transparent, if our subject was discursively constituted or rather materially situated, and if our subject can be discovered or rather constructed. ${ }^{25}$ Following their advice, I have tried to answer those critical questions in order to increase reflexivity in my research. Several overlapping bodies of theory underpin my research. First, a 'soft' Butlerian conception on subjects, meaning that I understand subjects mostly as constituted in and through the discourse/power matrix. ${ }^{26}$ My approach is 'soft' to the extent that it has been attenuated by the constant belief that discourses can also be empowering. ${ }^{27}$ Second, I assume a mitigated relativism, meaning that I believe I can make claims about how I believe the social world works, even though there will always be something completely unknown about it. ${ }^{28}$ Third, I build from a relational ontology; relying on an understanding of the self as constituted in and through

21 Yvonna S Lincoln, Susan A Lynham and Egon G Guba, 'Paradigmatic Controversies, Contradictions, and Emerging Controversies, Revisited' in N K Denzin and Y S Lincoln (eds), Sage Book of Qualitative Research (4th edn, Sage 2012) 97.

22 Ibid. 106.

23 Ibid 103.

24 Natasha S Mauthner and Andrea Doucet, 'Reflexive Accounts and Accounts of Reflexivity in Qualitative Data Analysis' (2003) 37 Sociology 413, 423.

25 Ibid 424.

26 Judith Butler, 'Contingent Foundations' in S Benhabib, J Butler, D Cornell and N Fraser (eds), Feminist Contentions: A Philosophical Exchange (Routledge 1995).

27 Nancy Fraser, 'False Antitheses' in Benhabib et al (n 26).

28 Dorothy Smith, The Everyday World as Problematic: A Feminist Sociology (Open University Press 1987). 
relations with others, rather than self-sufficient. ${ }^{29}$ Finally, I assume a discursive approach to law, seeing law as discursively constituting gender identities. ${ }^{30}$

The sculpture of the Huastec goddess has expanded my views and reflections about the subject of my research. For example, by examining the sculpture, individuality is invisible on first glance, but becomes apparent upon closer inspection. The sculpture appears to be an unsophisticated and slab-like artefact, but a more detailed examination reveals details that make it more human, such as her lips, eyes and the creases under her breasts. In a similar way, the AUH programme derives from the basis of an ideal, generic and stereotypical woman. It involves an approach to poverty that simultaneously erases women's individuality while framing poverty as an individual struggle - as opposed to seeing it as a collective one - which in turn contributes to eroding beneficiary women's aspirations and individual capabilities. This reflection also pertains to the predicaments of agency and voluntarism, on the one hand, and social and structural determinism, on the other.

Thinking in terms of my object and the visual representation of women as mothers provokes me to rethink my epistemological assumptions in order to be able to account for the complex interactions through which the social, the biological and the physical emerge, persist and transform the meaning and significance of motherhood in social policy. For example, the 'new materialist' feminists draw on the physical sciences and recognise the agency of matter in social and political phenomena, challenging the linear models of causation that underlie constructivist analyses of the ways power shapes the subjects and objects of knowledge. ${ }^{31}$ This understanding would involve a reconceptualisation - or a problematisation - of the interactions between biology and culture. $^{32}$ This epistemological challenge has expanded the assumptions in my work and pushes me to reconstruct the synergies that constitute subjects and objects, as FaustoSterling puts it, as '100\% nature and 100\% nurture'. ${ }^{33}$

My sculpture of the Huastec goddess has encouraged me to decentre human intentionality and to rethink and problematise the conceptualisation of the relationship between nature (pregnancy, fertility) and culture (the social construction of womanhood and motherhood) and the ways in which they interact in non-dichotomous ways, while capturing the reciprocally transformative nature of the relationship. The key insight in work by feminist new materialists is that biology and culture, subjects and objects, organisms and contexts shape one another as they are co-emergent, drawing attention to a network of interconnectedness. As Jane Bennett argues, 'humans are always in composition with nonhumanity, never outside of a sticky web of connections' ${ }^{34}$

Thinking about my object and positioning it within my research agenda has allowed me to find better conceptual tools to engage with and criticise essentialism by theoretically acknowledging and departing from the complex and recursive interactions between inorganic and organic materiality, rethinking the terms of causation through which nature and culture develop.

29 Carol Gilligan, In a Different Voice: Psychological Theory and Women's Development (Harvard University Press 1982).

30 Carol Smart, "The Woman of Legal Discourse" (1992) 1 Social and Legal Studies 29. See also Dorothy E Chunn and Dany Lacombe, 'Introduction' in Dorothy E Chunn and Dany Lacombe (eds), Law as a Gendering Practice (Oxford University Press 2000).

31 Samantha Frost, 'The Implications of the New Materialisms for Feminist Epistemology' in H E Grasswick (ed), Feminist Epistemology and Philosophy of Science: Power in Knowledge (Springer Netherlands 2011).

32 Elizabeth Grosz, The Nick of Time: Politics, Evolution, and the Untimely (Duke University Press 2004) 2.

33 Anne Fausto-Sterling, 'The Bare Bones of Sex: Part 1 - Sex and Gender' (2005) 30(2) SIGNS 1491, 1510.

34 Jane Bennett, 'The Force of Things: Steps toward an Ecology of Matter' (2004) 32(3) Political Theory 347, 365. 
As an institutional ethnographer, I am committed to the actualities of people's lives rather than to concepts, and this strategy has real implications for women's emancipation besides being an important critique of mainstream sociology. Indeed, researching from a particular location is one of the most important characteristics of institutional ethnography projects. With its focus on the individual experience, institutional ethnography does not mix well with an overwhelming emphasis on subjects' discursive constructions because it fails to consider that women have lives outside the text. This methodology challenges discursive fabrications of the subject as they erode decades of feminist struggle for women to speak from their own experience and for asserting their right to have their voices acknowledged.

Thus, thinking about my object in connection to my research agenda involved a shift towards thinking in terms of complex causation and interdependencies. Objects always exist in dynamic 'assemblages' and connections that affect what they are and how they behave. Accordingly, it does not make sense to conceive of an object as a bounded and distinct thing, as if it existed in isolation from other objects and humans. ${ }^{35}$ Admitting this interdependency allows me to confront the epistemological impossibility of complete and predictive knowledge of complex causal processes. There are therefore two important considerations when carrying out institutional ethnography that deserve to be highlighted. Because institutional ethnography researchers reject categorical descriptions and do not regard their informants as a 'sample', it is important to conceive selection of informants in terms of diversity of experience and/or circumstances, instead of in terms of categories. The second important consideration when researching in institutional ethnography is that investigations are not fully planned out in advance: 'The process of inquiry is rather like grabbing a ball of string, finding a thread, and then pulling it out.'36 Only step-by-step as a researcher do I realise and decide whom I need to interview and what documents I need to examine.

Epistemologically, thinking about my object has encouraged me to remember that knowing commences and concludes with a real, situated and embodied person. Thinking about subjects and objects in a coordinated rather than dichotomous way helps me resist taking for granted practices of knowing and not taking concepts as given. Concepts must explicate actual social relations. They should not merely be floating abstractions or nominal labels imposed as the status quo. The four-part 'ontological package' of institutional ethnography is thus basically that individuals are there; they are in their bodies; they are active; and what they are doing is coordinated with the doings of others' ${ }^{37}$ Since institutional ethnography parts from an 'ontology of the social', the first step is establishing the 'social' as the coordination of people's activities under specific material conditions. Individuals are unique and, therefore, variance of perspective is necessarily created in the very process of coordinating their doings.

\section{TRANSLATION AS AN ACT OF BETRAYAL? ETHICS, REFLEXIVITY AND LANGUAGE}

Finally, the sculpture of the Huastec goddess allowed me to engage and confront issues of ethics and reflexivity. Nobody involved in researching 'the social' can avoid confronting ethical issues. ${ }^{38}$ This is especially true in my research project because it engages marginalised populations.

35 Ibid 365.

36 George W Smith, cited in DeVault and McCoy (n 7 ) 7.

37 Smith (n 9) 59.

38 Sue Richardson and Miriam McMullen, 'Research Ethics in the UK: What Can Sociology Learn from Health?' (2007) 41(6) Sociology 115. 
The Huastec sculpture as a collected object allows me to highlight how interpretation is always an act of construction. When it comes to reading this sculpture, we are translating complex ideas from the Huastec culture, an annihilated culture with no written language. The Aztec empire was conquered by the Spaniards in the 1520s. Prior to that, the Aztecs had subjugated the Huastecs. There exists very little now that would enable us to reconstruct the culture and the ideas of the Huastecs. Therefore, in order to read the goddess sculpture, we need to pass through layers of interpretation by cultures with very different ways of understanding the world.

Indeed, all we have in order to understand the Huastec people are the Spanish accounts of the Aztec accounts of the people they had conquered - their liquidation of the Huastec. In turn, the Aztecs appropriated the Huastec mother goddess as their own mother goddess Tlazolteotl. This idea of the Huastec goddess, as appropriated by the Aztecs and explained by the Spanish conquerors, via a sculpture of a goddess displayed at a museum in London, allows me to see how a history of conquest, annihilation and imperialism heavily impacts on the ways we read the object in question. It also allows me to see how I am reading the object in light of my own epistemological and ontological assumptions, according to who I am and to how I see the world. Am I reading the object from a position of privilege? What are the biases and assumptions that I should be able to identify in my own project?

Indeed, we cannot think about translation from one culture to another without thinking about reflexivity, contro, and dominance. Reflexivity calls us to turn the gaze upon ourselves. Examining this object has been a call for self-reflexivity, which means that we are constantly engaged in constructing our physical and social world in particular ways and according to our own rationality.

The way we read this object involves a particular mode of seeing the world, of understanding it; it is conditioned by a particular ontology. The issue of translation of a lost Huastec voice from a lost culture, such as the Huastec culture into Aztec and then to Spanish, was a fruitful learning exercise. The original version of the research proposal for the purposes of my doctoral research stated as one of its objectives:

to give a voice to women who receive the transfer in order to understand their experiences, perceptions of themselves, interpretations of public attitudes towards them, as well as their own rationalisations of why they and others receive the grants, and the impact of conditional cash transfer programmes on their time, work, self-esteem and relation with other members of their household and community.

However, the problem of 'giving voice' is twofold. Firstly, it parts from the basis that my interviewees and participants do not already have a voice. Secondly, it assumes that a 'voice' is something that I as a researcher can 'give' to the women involved in the research.

Being dominant is a perennial problem for qualitative researchers. As Bell Hooks brilliantly put it, 'no need to hear your voice when I can talk about you better than you can speak about yourself ... I am still the author, authority. I am still the colonizer.'39 Thus, another specific challenge that I faced as a researcher was how to share control with my participants so that they ultimately can have a say on how research is conducted. ${ }^{40}$ The matter of control was very challenging in the course of my research project because it could be a means of redressing power imbalances, or it could instead impede

39 Bell Hooks, 'Postmodern Blackness' in Vincent B Leitch (ed), The Norton Anthology: Theory and Criticism (WW Norton \& Company 2000).

40 Lincoln et al (n 21) 118. 
empowerment and emancipation. So far, I have realised that I have initiated the conversation, crafted and stipulated the set of questions, determined what constituted a finding, decided on how to represent the information and what aspects would be highlighted, and decided how participants were represented. This is problematic to the extent that I perceived myself as dominating the research. I then became painfully aware of the need for my participants to take an increasing and more active role in my research in the future stages of my project by designing outlets for sharing the findings fairly and openly within the community and paying specific attention to community member validation of my findings. 41

The aforementioned problem of dominance of my voice and my own privilege as a researcher was a constant one while gathering qualitative data. In order to soften my apprehensions about being dominant and ethnocentric, I have tried to rely on critical subjectivity and self-awareness. Reflexivity did not originate in academia as mere egocentrism or self-adoration. As Roberston clearly explains:

Twenty years ago, reflexivity was proposed as a corrective to a mode of ethnographic writing in which factual material was presented by an omniscient yet invisible author-narrator whose methods of fieldwork and data collecting were not always manifest, and who did not address the effect of her or his presence on others, much less the various effects that others may have had on her or him. ${ }^{42}$

The first step I took in 'doing' reflexivity was to make myself very uncomfortable and aware of my privilege as a researcher, a privilege that is much more ostensible when researching marginalised communities. I scrutinised my own values, my ambitions, my intentions and my convictions as a researcher. I tried to position myself in the political and social landscape, being open about my research persona by filling in the fashionable 'badges', ${ }^{43}$ such as those that indicate ideology or value systems - I am a feminist, a socialist - and those that show my positionality in the social and political landscape that I inhabit as a researcher - cis-gender female, from the Global South, agnostic, heterosexual, able-bodied, middle-class, educated, a mother.

However, positionality is not without its problems. Egocentrism is one of the central problems to encounter when exercising excessive reflexivity. ${ }^{44}$ The aforementioned badges have been criticised as being problematically endemic to American universities and as 'hav[ing] been packaged as "ready to wear" consumables guaranteed to clarify one's location or position within the undulating academic landscape'. ${ }^{45}$ Thus, displaying my 'badges' at the early stages of research - specifically regarding the power differentials of the research relation - is not satisfactory, as 'researchers do not only bring ourselves to the field, but we also create ourselves in the field'. ${ }^{4}$

The problem of writing in the name of '[insert predetermined category here]' is that it precedes the research experience, creating an illusion of self-awareness, while actually effacing the researcher's very complex life. Thus, the real challenge of being reflexive was

41 Michael Bloor, 'Techniques of Validation in Qualitative Research: A Critical Commentary' in Contemporary Field Research: Perspectives and Formulations (2nd edn, R Emerson 1997) 385, 387.

42 Jennifer Robertson, 'Reflexivity Redux: A Pithy Polemic on 'Positionality" (2002) 75 Anthropological Quarterly 785.

43 Mauthner and Doucet (n 24) 413.

44 Roberston (n 42) 786.

45 Ibid 788.

46 Lincoln et al (n 21) 124. 
to do so at the time of conducting the research and analysing the data, while simultaneously being fluid and rejecting those generic and fixed categories.

The legal object of the Huastec goddess - as read through the layers of Huastec, Aztec, and Spanish cultures - also impacted my understanding of the boundaries between 'insider' and 'outsider'. Some legal scholars, such as Vivian Grosswald Curran, for example, state that cultural immersion is a prerequisite when analysing a legal system. The author emphasises the need to adopt an inside perspective (emic) as opposed to only an outsider perspective (etic) of the legal system. Having been raised and educated in Argentina, and extensively studied its legal system, the aforementioned need for an 'emic' perspective did not seem to be a hindrance. However, legal comparativist scholars such as Grosswald Curran also argue that the researcher needs to maintain the position of an outsider even as she attains understanding of the insider's perspective. The researcher 'must render the foreign familiar and preserve its very foreignness at one and the same time'. ${ }^{47} \mathrm{I}$ have lived in Canada long enough to realise that my immersion in the Argentine cultural context has been, to some extent, compromised, and that I oscillate between being an insider and an outsider in both social, legal and cultural systems. I am supposed to position myself halfway between the pull between the emic and the etic, creating a mental space where a bijural mentality can ripen. This requirement may not sound terribly problematic to imagine, but Vernon Valentine Palmer requests forgiveness for asking "who has actually achieved this and how is it done? Are only high priests capable of meeting these demands? 48

Even though I am aware that I must maintain my stance as an outsider, a detached researcher, while simultaneously adopting the perspective of my participants and taking their standpoint, I am aware that I will always be as much of an outsider as I am an insider. I was challenged by, and struggled with, the nuanced entanglement of participant and subject. I also struggled with balancing the integrity of the research with the emotional work of engaging my participants. I am thus inspired by the sculpture of the mother goddess to take the challenge of the dynamics between the emic and the etic as a learning exercise which helps me to avoid ethnocentricity and superficiality, by delving beyond judicial decisions, doctoral writings and the black letter law of code and statute of the AUH and reaching into the grey region of deeper structures where law meets sociology, philosophy and culture.

\section{Conclusion}

This paper has explained how the sculpture of a Huastec goddess has caused me to reflect differently on my doctoral dissertation work. Firstly, I introduced the object in question and briefly described its material properties. Secondly, I provided a general outline of the substantive topic I research - the practice of CCT programmes in the context of gender equality in Argentina. Thirdly, I explained the methodologies and qualitative research methods which have informed my work to date and which are currently deployed.

Finally, I explained how the object in question - sculpture of the Huastec Goddess has helped me to reflect on the existing methodologies used in the project. It did so by

47 Vincent Crapanzo, 'Herme's Dilemma: The Masking of Subversion in Ethnographic Description' in James Clifford and George Marcus (eds), Writing Culture: The Poetics and Politics of Ethnography (University of California Press 1986) 52.

48 Vernon Valentine Palmer, 'From Lerotholi to Lando: Some Examples of Comparative Law Methodology' (2005) 53 American Journal of Comparative Law 261. 
impacting on my research methods in different ways. Firstly, it has allowed me to emphasise the instrumentalisation of beneficiary women and to explain how women are actually conduits through which resources from the state are delivered to children. In this way, my object allowed me to point out how these social policy initiatives contribute to entrenching oppressive cultural understandings of what womanhood should look like in the context of Argentina. Secondly, the Huastec sculpture has challenged my epistemological assumptions by allowing me to think more carefully about the dynamics between structure and agency and the possibilities and constraints to individuality versus more communitarian approaches to understanding poverty. Thirdly, the Huastec sculpture as a collected artefact which has passed through layers of interpretation and travelled from culture to culture has encouraged me to think more carefully about the ethical implications of qualitative research, about my role as a researcher and the dangers of become a 'coloniser', and about reflexivity and its limitations - control and dominance.

In conclusion, the sculpture of the Huastec goddess has challenged me as a researcher to understand objects as active evidence of a culture rather than as passive descriptions, making me aware of my own epistemological and ontological assumptions, challenging the false dichotomy between subject and objects, the social and the biological/material, and encouraging me to analyse my own privileges and my interpretations of the world as acts of social constructions. 